\title{
Educational inequalities in mortality and associated risk factors: German- versus French- speaking Switzerland
}

\author{
David Faeh ${ }^{\dagger}$, Matthias Bopp ${ }^{*}$, Swiss National Cohort Study Group
}

\begin{abstract}
Background: Between the French- and German-speaking areas of Switzerland, there are distinct differences in mortality, similar to those between Germany and France. Assessing corresponding inequalities may elucidate variations in mortality and risk factors, thereby uncovering public health potential. Our aim was to analyze educational inequalities in all-cause and cause-specific mortality in the two Swiss regions and to compare this with inequalities in behavioural risk factors and self-rated health.

Methods: The Swiss National Cohort, a longitudinal census-based record linkage study, provided mortality and survival time data (3.5 million individuals, 40-79 years, 261,314 deaths, 1990-2000). The Swiss Health Survey 1992/93 provided cross-sectional data on risk factors. Inequalities were calculated as percentage of change in mortality rate (survival time, hazard ratio) or risk factor prevalence (odds ratio) per year of additional education using multivariable Cox and logistic regression.

Results: Significant inequalities in mortality were found for all causes of death in men and for most causes in women. Inequalities were largest in men for causes related to smoking and alcohol use and in women for circulatory diseases. Gradients in all-cause mortality were more pronounced in younger and middle-aged men, especially in German-speaking Switzerland. Mortality inequalities tended to be larger in German-speaking Switzerland whereas inequalities in associated risk factors were generally more pronounced in French-speaking Switzerland.
\end{abstract}

Conclusions: With respect to inequalities in mortality and associated risk factors, we found characteristic differences between German- and French-speaking Switzerland, some of which followed gradients described in Europe. These differences only partially reflected inequalities in associated risk factors.

\section{Background}

Social inequalities in all-cause and cause-specific mortality have been reported for many European countries, including Switzerland [1,2]. However, in general there is a serious lack of comparable data [3]. Comparisons between countries are also hampered by the prevailing use of aggregated instead of individual data. Even when adequate data are available, it can still be difficult to assess inequalities because of nationally different definitions of socio-economic status (SES) and substantial variation regarding assignment of causes of death or

\footnotetext{
* Correspondence: bopp@ifspm.uzh.ch

† Contributed equally

Institute of Social and Preventive Medicine (ISPM), University of Zurich, Hirschengraben 84, 8001 Zurich, Switzerland
}

assessment of risk factors (including self-rated health) between countries [4-6]. The coarse definition and classification of SES makes it often difficult to compare inequality in mortality from specific causes. This lack of comparable data precludes exploring possible explanations for inequalities in mortality.

Regional comparisons may identify potential for reduction of inequalities. Switzerland offers a unique setting because it combines cultural diversity within common health care and statistical systems. A recent comparison showed characteristic variations in causespecific mortality and risk factors between the Germanand French-speaking areas of Switzerland reflecting broader European patterns [7]. Such variations indicate unexploited potential for reduction of health 
inequalities. Regional differences in socioeconomic characteristics are minor. Compared to German-speaking areas, in French-speaking Switzerland there is a slightly lower proportion of persons with intermediate education and a higher proportion with high and low education (see Additional file 1, Table S2). Economic and wealth parameters are comparable, except of a slightly higher unemployment rate in French-speaking Switzerland.

We sought to elucidate the contribution of SES inequalities in mortality and risk factors to regional differences in mortality and to look for parallels in European populations. To date, no such comparison of inequality between the two major linguistic regions of Switzerland is available. The purpose of this study was to analyse variations between the French- and Germanspeaking areas of Switzerland in educational inequalities in 1) cause-specific mortality and to compare them with 2) inequalities in associated risk factors. We used two different data sets: 1) census linked mortality data and 2) health survey data.

\section{Methods}

\section{Assessment of Mortality: Swiss National Cohort}

The Swiss National Cohort is a national longitudinal research platform based on anonymous record linkage of data collected by the Swiss Federal Statistical Office. The core cohort consists of the 6.874 million residents who participated in the 1990 census and were evaluated for a linkage with the 2000 census, a mortality or an emigration record; for $93.1 \%$ of this population a satisfactory link could be established (for more details see [8]). The 1990 and 2000 censuses in Switzerland were carried out with self-administered questionnaires. Nonparticipation is considered to be very low (coverage for 2000 census: 98.6\%) [9]. Of all registered deaths between the 1990 and the 2000 censuses, $95.3 \%$ could be successfully linked to the Swiss National Cohort [10]. For this study individuals were followed up in the period between Dec 4, 1990, and Dec 5, 2000 (census dates). Because of low mortality at young age and strong survival selection and difficulties in unicausal assignment of causes of death at oldest age, we limited the analyses to those aged between 40 and 79 . We did not impose a limit at 65 because some risk factors have a very long latency and limitation would have hampered comparison of inequalities in mortality and risk factors. Deaths and person years were accumulated only for that age group. Thus, the youngest observed subject had just passed his 30th birthday on Dec 4, 1990, and contributed only one day of observation on Dec 4, 2000. Individuals aged 80 and older at the 1990 census were excluded and those reaching their 80th birthday between the census dates were censored. Overall, we included all Swiss and foreign nationals satisfactorily linked to a mortality or 2000 census record and living in the German-speaking (GS, $\mathrm{n}$ $=2,629,271)$ or French-speaking areas of Switzerland (FS, $\mathrm{n}=820,849$ ), respectively. Because cell sizes were too small, we had to exclude the Italian-speaking areas of the country (less than $5 \%$ of total population).

\section{Assessment of SES}

For the determination of SES, we used two approaches. For regression analysis, we used level and estimated years of education (between 8 and 19 years respectively, for details see Additional file 1, Table S1). For descriptive mortality and prevalence (\%) rates, we reclassified the denotations used in the census and the survey into three educational categories: 1) less than secondary: compulsory schooling or less (International Standard Classification of Education, ISCED 1-2); 2) secondary: vocational training or high school (ISCED 3-4); 3) tertiary: technical colleges and upper vocational education and university education (ISCED 5-6) [11]. Mean years of education by educational category and proportion by year of education are shown in the Additional file 1, Table S1.

\section{Assessment of risk factors}

Data on risk factors stem from the first Swiss Health Survey $1992 / 1993$. The health survey is a cross-sectional, nationwide, population-based telephone survey conducted every 5 years by the Swiss Federal Statistical Office to monitor public health trends. The survey was completed by 15,288 participants ( 15 years and older, $71 \%$ participation rate, $52 \%$ women, for more details see [12]).

In line with the mortality analysis, we limited the age range to 40-79 years for a total of 7,378 persons (for more details see Additional file 1, Table S2). For simplicity, we defined only risk (and not protective) factors with alcohol as having positive and negative effects on health. Risk factors were defined as follows: "Current smoking" when smoking $\geq 1$ cigarette/day; "daily alcohol consumption" when drinking alcohol at least once per day; "infrequent fruit consumption" when not eating fruits daily; "physical inactivity" when not sweating at least once per week by performing physical activity in leisure time. Obesity was defined as Body Mass Index (= weight $\left./(\text { height })^{2}\right) \geq 30 \mathrm{~kg} / \mathrm{m}^{2}$. Although self-rated health may be regarded as a risk marker and not as a risk factor per se, we treat it like a risk factor in our study. Possible answers for rating one's own health were "very good", "good", "fair", "poor", "very poor". We subsumed the latter three into a single category "less-than-good health".

\section{Statistical analysis}

Age-standardized mortality rates and prevalence rates were calculated as described $[7,13]$. We performed 
analyses on the main groups of causes of death (diseases of the circulatory system, cancers, other diseases, and injuries) and on causes related to smoking and alcohol consumption. Types of cancers included upper aerodigestive tract (UADT: oropharynx, larynx, oesophagus), stomach, intestine, liver, lung, prostate and female breast. Table S3 (Additional file 1) shows the ICD (International Classification of Diseases) 8/9 and ICD 10 codes of selected causes of death. In Switzerland ICD-8 was used until 1994 followed by ICD-10 thereafter.

Since categorization of education into three levels loses valuable information, we used years of education instead. We calculated the relative change of hazard ratios (mortality rates) and odds ratios (risk factors prevalence), with every year of education in addition to lowest education (8 years). This was done using individual data and Cox regression (for modelling survival in cohort data) and logistic regression (for modelling the prevalence of risk factors in the health survey data) with years of education as independent variable. For the analysis of the health survey data we added age (linear and quadratic; the quadratic term was introduced to allow for a progressive increase of mortality with age) to the model and weighted proportions to the Swiss population. The STATA command "stcox" automatically adjusts for age (linear and exponential). In order to quantify differences (with p-values) in educational gradients between German and French-speaking Switzerland, we included in the model, in addition to the region variable, an interaction term (region times years of education).

As shown in Additional file 1, Table S1, with respect to demographic characteristics, there are only small differences between the cohort population and the health survey sample (except for those with tertiary education). As sensitivity analysis, we calculated the Relative Index of Inequality (RII) $[1,14]$. The RII provided a very similar pattern of inequality but larger confidence intervals. Therefore, we preferred the year-of-education-approach. The use of RII is necessary when data are aggregated or when parameters of inequality differ as is often the case between countries. With individual data and a uniform definition of SES, we could better exploit data with the year-of-education approach and avoid the loss of information. With both the cohort and health survey data, we also performed analysis excluding foreign nationals which did not change estimates significantly (not shown). Analyses were performed with STATA SE (Version 9, StataCorp, College Station, TX).

\section{Results}

Overall 3,450,120 persons accumulating 26,734,458 person-years were included: $1,278,052$ men and 1,351,219 women from GS; and 392,451 men and 428,398 women from FS. Details are shown in the Additional file 1, Table S2.

\section{Inequality in mortality}

As shown in figure 1, all-cause mortality per additional year of education decreased in the youngest age group by about 7\% (FS) and 9\% (GS) in men and by about $6 \%$ (FS) and 4\% (GS) in women. In GS men aged 50-59 years, those with the lowest education (11 years of maximum education difference with $10.51 \%$ increase per year of education: 1.1051 to the power of $11=3.0$ ) had a three times higher all-cause mortality risk compared to those with the highest education. In men but not in women, inequalities appeared to decrease with age. In men, inequalities were significantly larger in GS than in FS in all age groups. This was also true in women except for the youngest age group.

Table 1 and 2 show counts and mortality rates (per 100,000 person-years) for selected causes of death by region and sex, overall and by educational level. The tables also give the percentage change of mortality rate for each additional year of education. Almost all of the educational gradients were mathematically monotonical. In men, there was a significant educational gradient for all causes of death in both regions except for prostate cancer in FS. The largest inequalities were found for UADT, stomach and lung cancer, COPD and liver cirrhosis. In women significant inequality gradients (confidence intervals excluded zero) were less frequent and generally restricted to circulatory disease, stomach cancer and alcohol-(liver cirrhosis) or smoking-related (COPD, lung cancer) causes of death. In GS, ill-defined causes and suicide showed a significant inverse gradient.

In both regions, inequalities were larger in men than in women for mortality from all-causes, cancer (particularly UADT, stomach in FS and lung), COPD, liver cirrhosis, suicide and transport accidents, while they were larger in women than men for coronary heart disease (CHD) and stroke mortality.

Relative differences between FS and GS were more pronounced in men than in women. However, only few differences were significant $(\mathrm{p}<0.05$, in men: all causes, all circulatory, other heart diseases, lung cancer, COPD, transport accidents, alcohol and smoking-related causes; in women: all causes and ill-defined causes) or tended to be significant ( $\mathrm{p}<0.1$, in men: coronary heart disease, UADT and stomach cancer; in women: all cancer and UADT cancer).

In men, the gradients were (or tended to be) steeper in GS than in FS for all 21 entities except for 5: suicide, intestinal and prostate cancer, ill-defined causes and all injuries. As in men, also in women, inequality in allcause mortality and transport accidents was significantly larger in GS. However, inequality tended to be larger in 


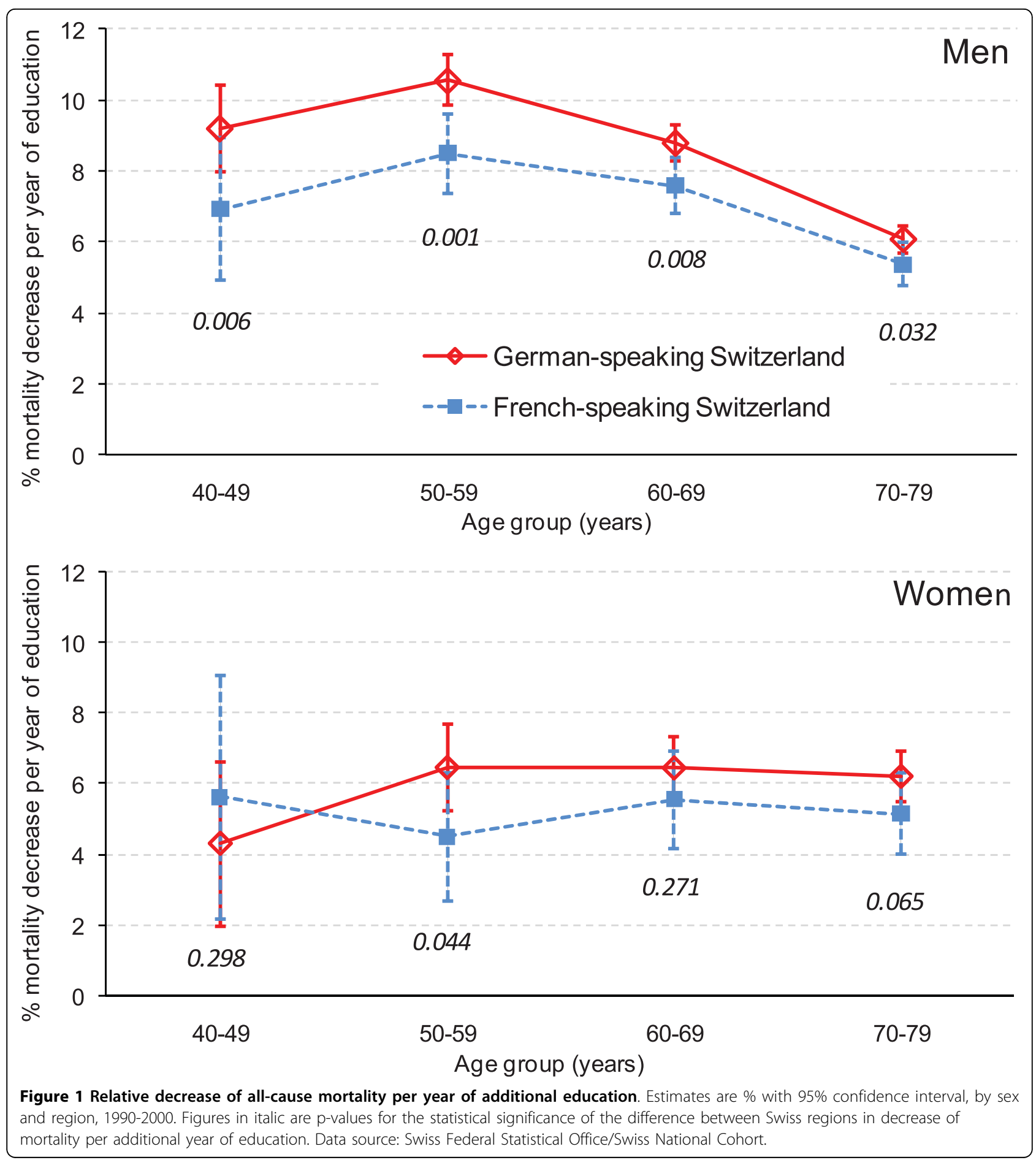

FS than in GS for CHD, liver, lung and breast cancer, liver cirrhosis, suicide, ill-defined and alcohol-related causes.

\section{Inequality in risk factors}

Table 3 shows the number of participants with risk factors, prevalence of risk factors overall and by educational level and relative change per year of education. Except for obesity in women, the prevalence of risk factors tended to be higher in FS than in GS, with the largest relative difference in daily fruit consumption. In men, inequalities in all risk factors were larger in FS, except for less-than-good health. In women, inequalities were larger in FS than in GS only for current smoking 
Table 1 Inequality in mortality in Switzerland by language region and cause of death in men

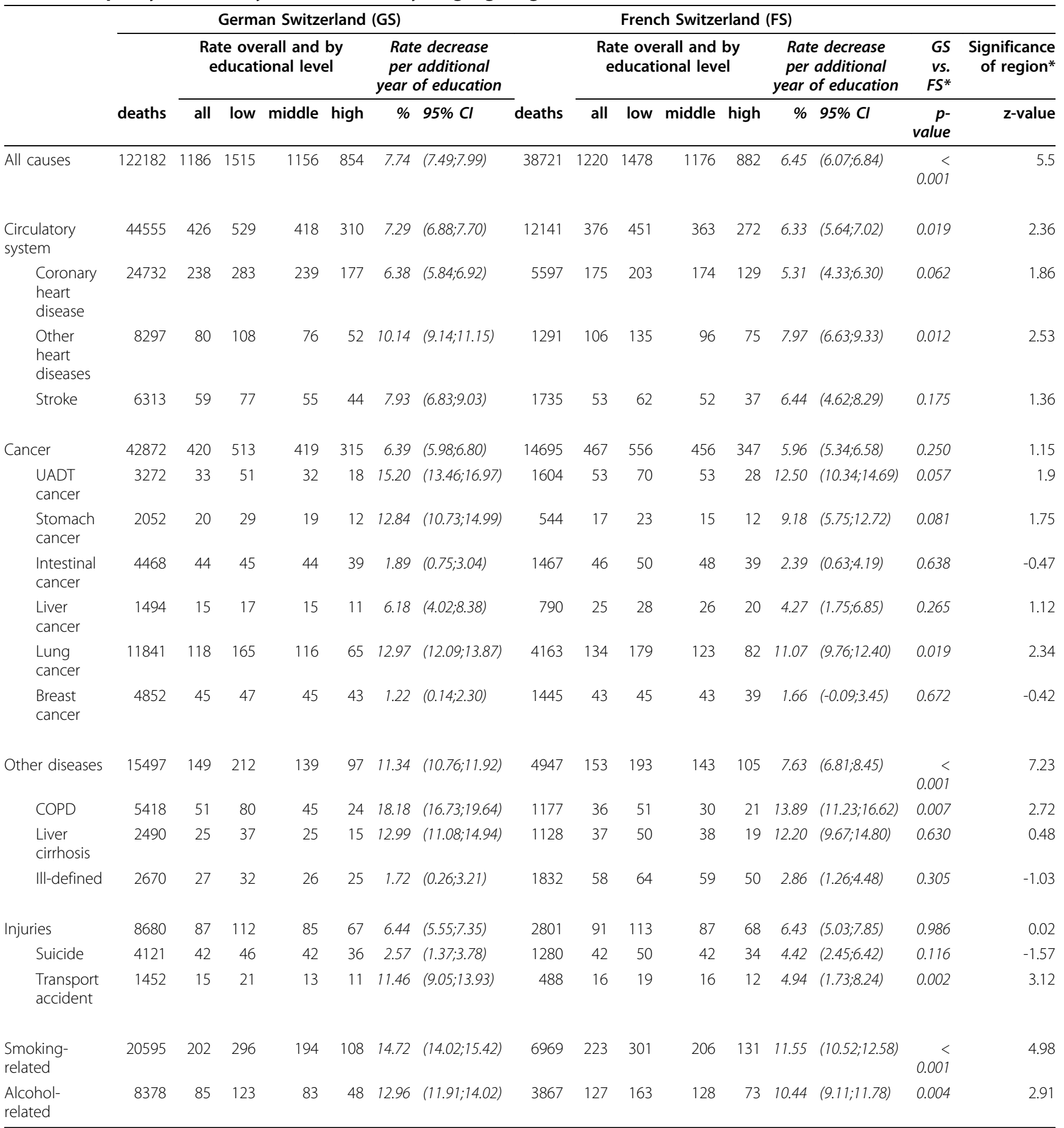

* Statistical significance of the difference between Swiss regions in decrease of mortality per additional year of education 1990-2000, 40-79 years

UADT: Upper aerodigestive tract; COPD: Chronic obstructive pulmonary disease ISCED: International Standard Classification of Education

Educational level: low $=$ no secondary or tertiary education (ISCED 1-2), middle = secondary education (ISCED 3-4); high $=$ tertiary education (ISCED 5-6)

Rates were standardized to the WHO standard population "Europe" [13]

Data source: Swiss Federal Statistical Office/Swiss National Cohort 
Table 2 Inequality in mortality in Switzerland by language region and cause of death in women

\begin{tabular}{|c|c|c|c|c|c|c|c|c|c|c|c|c|c|c|c|c|}
\hline & \multicolumn{7}{|c|}{ German Switzerland (GS) } & \multicolumn{7}{|c|}{ French Switzerland (FS) } & \multirow{3}{*}{$\begin{array}{r}G S \\
v s . \\
F S^{*}\end{array}$} & \multirow{3}{*}{$\begin{array}{r}\begin{array}{r}\text { Significance } \\
\text { of region* }\end{array} \\
\text { z-value }\end{array}$} \\
\hline & \multirow[b]{2}{*}{ deaths } & \multicolumn{4}{|c|}{$\begin{array}{l}\text { Rate overall and by } \\
\text { educational level }\end{array}$} & \multicolumn{2}{|c|}{$\begin{array}{c}\text { Rate decrease } \\
\text { per additional } \\
\text { year of education }\end{array}$} & \multirow[b]{2}{*}{ deaths } & \multicolumn{4}{|c|}{$\begin{array}{l}\text { Rate overall and by } \\
\text { educational level }\end{array}$} & \multicolumn{2}{|c|}{$\begin{array}{c}\text { Rate decrease } \\
\text { per additional } \\
\text { year of education }\end{array}$} & & \\
\hline & & all & low & middle & high & $\%$ & $95 \% \mathrm{Cl}$ & & all & low & middle & high & $\%$ & $95 \% \mathrm{Cl}$ & & \\
\hline All causes & 77227 & 600 & 668 & 533 & 481 & 6.17 & $(5.77 ; 6.58)$ & 23184 & 572 & 629 & 502 & 462 & 5.07 & $(4.42 ; 5.72)$ & 0.004 & 2.84 \\
\hline $\begin{array}{l}\text { Circulatory } \\
\text { system }\end{array}$ & 24935 & 177 & 209 & 141 & 110 & 11.42 & $(10.61 ; 12.23)$ & 6780 & 153 & 180 & 115 & 97 & 11.20 & $(9.75 ; 12.68)$ & 0.801 & 0.25 \\
\hline $\begin{array}{l}\text { Coronary } \\
\text { heart } \\
\text { disease }\end{array}$ & 10743 & 76 & 90 & 59 & 46 & 12.13 & $(10.88 ; 13.39)$ & 2368 & 53 & 65 & 37 & 29 & 14.23 & $(11.58 ; 16.95)$ & 0.160 & -1.4 \\
\hline $\begin{array}{l}\text { Other } \\
\text { heart } \\
\text { diseases }\end{array}$ & 5223 & 37 & 44 & 31 & 24 & 9.76 & $(8.06 ; 11.48)$ & 2201 & 50 & 57 & 40 & 34 & 8.99 & $(6.59 ; 11.45)$ & 0.612 & 0.51 \\
\hline Stroke & 2627 & 38 & 44 & 31 & 24 & 10.22 & $(8.53 ; 11.94)$ & 681 & 31 & 36 & 24 & 21 & 9.18 & $(6.14 ; 12.31)$ & 0.562 & 0.58 \\
\hline Cancer & 30890 & 256 & 269 & 244 & 233 & 2.46 & $(1.87 ; 3.05)$ & 9464 & 248 & 259 & 240 & 225 & 1.55 & $(0.65 ; 2.46)$ & 0.098 & 1.66 \\
\hline $\begin{array}{l}\text { UADT } \\
\text { cancer }\end{array}$ & 717 & 6 & 7 & 6 & 4 & 4.19 & $(0.26 ; 8.27)$ & 324 & 9 & 9 & 9 & 7 & 3.40 & $(-1.56 ; 8.60)$ & 0.062 & 1.87 \\
\hline $\begin{array}{l}\text { Stomach } \\
\text { cancer }\end{array}$ & 1038 & 8 & 10 & 6 & 6 & 13.61 & $(9.65 ; 17.71)$ & 319 & 8 & 9 & 7 & 6 & 6.87 & $(1.25 ; 12.81)$ & 0.547 & -0.6 \\
\hline $\begin{array}{l}\text { Intestinal } \\
\text { cancer }\end{array}$ & 3165 & 25 & 25 & 25 & 24 & 0.42 & $(-1.36 ; 2.23)$ & 932 & 23 & 23 & 23 & 20 & 0.27 & $(-2.53 ; 3.15)$ & 0.932 & 0.09 \\
\hline $\begin{array}{l}\text { Liver } \\
\text { cancer }\end{array}$ & 515 & 4 & 4 & 4 & 3 & 3.75 & $(-0.91 ; 8.63)$ & 195 & 5 & 6 & 4 & 4 & 6.82 & $(-0.36 ; 14.51)$ & 0.490 & -0.69 \\
\hline $\begin{array}{l}\text { Lung } \\
\text { cancer }\end{array}$ & 3189 & 28 & 30 & 27 & 23 & 2.46 & $(0.64 ; 4.31)$ & 1285 & 34 & 38 & 33 & 29 & 4.06 & $(1.50 ; 6.69)$ & 0.317 & -1 \\
\hline $\begin{array}{l}\text { Breast } \\
\text { cancer }\end{array}$ & 7146 & 63 & 61 & 63 & 66 & -1.01 & $(-2.14 ; 0.13)$ & 2099 & 58 & 59 & 58 & 55 & 0.41 & $(-1.38 ; 2.23)$ & 0.186 & -1.32 \\
\hline Other diseases & 12898 & 96 & 113 & 80 & 70 & 7.86 & $(6.98 ; 8.76)$ & 3698 & 86 & 100 & 69 & 58 & 7.64 & $(6.23 ; 9.07)$ & 0.791 & 0.26 \\
\hline COPD & 2047 & 15 & 18 & 13 & 9 & 8.52 & $(5.89 ; 11.22)$ & 505 & 12 & 13 & 10 & 9 & 7.58 & $(2.84 ; 12.54)$ & 0.738 & 0.33 \\
\hline $\begin{array}{l}\text { Liver } \\
\text { cirrhosis }\end{array}$ & 1209 & 11 & 13 & 10 & 10 & 5.40 & $(2.36 ; 8.53)$ & 418 & 12 & 14 & 10 & 9 & 9.62 & $(4.72 ; 14.76)$ & 0.153 & -1.43 \\
\hline III-defined & 1331 & 11 & 11 & 11 & 17 & -4.97 & $(-7.36 ;-2.53)$ & 1014 & 26 & 27 & 24 & 26 & 2.01 & $(-0.76 ; 4.86)$ & 0.001 & -3.75 \\
\hline Injuries & 3917 & 34 & 35 & 33 & 33 & 0.91 & $(-0.66 ; 2.50)$ & 1305 & 35 & 36 & 34 & 39 & 0.40 & $(-1.83 ; 2.69)$ & 0.718 & 0.36 \\
\hline Suicide & 1751 & 16 & 16 & 17 & 18 & -2.22 & $(-4.36 ;-0.03)$ & 574 & 17 & 17 & 17 & 19 & -1.17 & $(-4.28 ; 2.05)$ & 0.587 & -0.54 \\
\hline $\begin{array}{l}\text { Transport } \\
\text { accident }\end{array}$ & 509 & 4 & 5 & 4 & 3 & 2.61 & $(-1.82 ; 7.25)$ & 205 & 5 & 5 & 6 & 7 & -2.45 & $(-7.57 ; 2.95)$ & 0.149 & 1.44 \\
\hline $\begin{array}{l}\text { Smoking- } \\
\text { related }\end{array}$ & 5980 & 49 & 54 & 46 & 36 & 4.78 & $(3.37 ; 6.20)$ & 2128 & 55 & 61 & 52 & 45 & 4.25 & $(2.21 ; 6.33)$ & 0.678 & 0.42 \\
\hline $\begin{array}{l}\text { Alcohol- } \\
\text { related }\end{array}$ & 2861 & 25 & 28 & 24 & 20 & 4.59 & $(2.61 ; 6.61)$ & 1050 & 29 & 33 & 26 & 22 & 7.44 & $(4.41 ; 10.57)$ & 0.123 & -1.54 \\
\hline
\end{tabular}

*Statistical significance of the difference between Swiss regions in decrease of mortality per additional year of education 1990-2000, 40-79 years

ISCED: International Standard Classification of Education

UADT: Upper aerodigestive tract; COPD: Chronic obstructive pulmonary disease

Educational level: low = no secondary or tertiary education (ISCED 1-2), middle = secondary education (ISCED 3-4); high = tertiary education (ISCED 5-6)

Rates were standardized to the WHO standard population "Europe" [13]

Data source: Swiss Federal Statistical Office/Swiss National Cohort 
Table 3 Inequality in risk factors prevalence in Switzerland by language region and sex

\begin{tabular}{|c|c|c|c|c|c|c|c|c|c|c|c|c|c|c|c|}
\hline & \multicolumn{7}{|c|}{ German-speaking Switzerland } & \multicolumn{7}{|c|}{ French-speaking Switzerland } & \multirow{3}{*}{ GS vs. FS* } \\
\hline & \multirow[b]{2}{*}{$\mathbf{N}$} & \multicolumn{4}{|c|}{$\begin{array}{l}\text { Prevalence (\%) overall } \\
\text { and by educational } \\
\text { level }\end{array}$} & \multicolumn{2}{|c|}{$\begin{array}{c}\text { Prevalence } \\
\text { decrease per } \\
\text { additional year of } \\
\text { education }\end{array}$} & \multirow[b]{2}{*}{$\mathbf{N}$} & \multicolumn{4}{|c|}{$\begin{array}{c}\text { Prevalence (\%) overall } \\
\text { and by educational } \\
\text { level }\end{array}$} & \multicolumn{2}{|c|}{$\begin{array}{c}\text { Prevalence } \\
\text { decrease per } \\
\text { additional year of } \\
\text { education }\end{array}$} & \\
\hline & & all & low & middle & high & $\%$ & $95 \% \mathrm{Cl}$ & & all & low & middle & high & $\%$ & $95 \% \mathrm{Cl}$ & \\
\hline \multicolumn{16}{|l|}{ Men $(N=3,241)$} \\
\hline Current smoking & 579 & 23 & 21 & 26 & 18 & 6.46 & $(6.27 ; 6.66)$ & 260 & 28 & 32 & 30 & 24 & 6.99 & $(6.70 ; 7.29)$ & 0.004 \\
\hline Daily alcohol consumption & 815 & 35 & 41 & 35 & 31 & 4.08 & $(3.91 ; 4.24)$ & 465 & 52 & 56 & 54 & 45 & 4.80 & $(4.55 ; 5.05)$ & $<0.001$ \\
\hline Infrequent fruit consumption & 719 & 26 & 31 & 30 & 29 & 2.39 & $(2.22 ; 2.55)$ & 338 & 30 & 33 & 38 & 33 & 4.66 & $(4.40 ; 4.93)$ & $<0.001$ \\
\hline Physical inactivity & 812 & 33 & 42 & 35 & 27 & 7.12 & $(6.95 ; 7.30)$ & 336 & 36 & 45 & 37 & 29 & 8.52 & $(8.24 ; 8.80)$ & $<0.001$ \\
\hline Obesity & 198 & 9 & 15 & 8 & 8 & 12.80 & $(12.5 ; 13.1)$ & 82 & 8 & 13 & 8 & 5 & 18.12 & $(17.6 ; 18.7)$ & $<0.001$ \\
\hline Less-than-good health & 394 & 16 & 21 & 18 & 11 & 7.38 & $(7.15 ; 7.61)$ & 171 & 19 & 30 & 17 & 14 & 7.32 & $(6.97 ; 7.67)$ & 0.769 \\
\hline \multicolumn{16}{|l|}{ Women $(N=4,137)$} \\
\hline Current smoking & 566 & 19 & 19 & 18 & 22 & 4.30 & $(4.05 ; 4.54)$ & 285 & 22 & 23 & 24 & 17 & 8.32 & $(7.98 ; 8.67)$ & $<0.001$ \\
\hline Daily alcohol consumption & 311 & 10 & 9 & 10 & 14 & -7.76 & $(-8.00 ;-7.50)$ & 320 & 28 & 23 & 33 & 23 & -3.30 & $(-3.67 ;-3.03)$ & $<0.001$ \\
\hline Infrequent fruit consumption & 471 & 10 & 15 & 14 & 12 & 5.38 & $(5.10 ; 5.70)$ & 308 & 20 & 29 & 22 & 23 & 6.09 & $(5.77 ; 6.41)$ & 0.001 \\
\hline Physical inactivity & 1209 & 39 & 47 & 35 & 36 & 9.17 & $(8.96 ; 9.38)$ & 555 & 47 & 53 & 46 & 35 & 7.52 & $(7.24 ; 7.80)$ & $<0.001$ \\
\hline Obesity & 214 & 7 & 11 & 6 & 3 & 27.01 & $(26.5 ; 27.5)$ & 80 & 6 & 10 & 5 & 3 & 26.99 & $(26.3 ; 27.7)$ & 0.960 \\
\hline Less-than-good health & 588 & 19 & 25 & 16 & 12 & 12.50 & $(12.2 ; 12.8)$ & 319 & 27 & 35 & 22 & 22 & 8.70 & $(8.36 ; 9.05)$ & $<0.001$ \\
\hline
\end{tabular}

* Statistical significance of the difference between Swiss regions in decrease of mortality per additional year of education 1992/93, 40-79 years

$\mathrm{N}$ : Number of persons reporting respective risk factors

Educational level: low = no secondary or tertiary education (ISCED 1-2), middle = secondary education (ISCED 3-4); high = tertiary education (ISCED 5-6)

Data source: Swiss Federal Statistical Office, Swiss Health Survey 1992/93

and infrequent fruit consumption. Inequalities were reversed ("negative") for alcohol consumption in women (i.e., more frequent consumption by those with higher education). The largest inequalities were found for obesity, particularly in women.

\section{Discussion}

We examined educational inequalities in mortality, related risk factors (including self-rated health) in the French- and German-speaking areas of Switzerland. In both regions, the largest inequalities were found in men in mortality from causes related to smoking and alcohol consumption, and in women from circulatory diseases and stomach cancer. Mortality inequalities tended to be larger in German than in French-speaking Switzerland (particularly in men). Regional inequality differences in the corresponding risk factors generally failed to explain variations in mortality inequalities. In both regions, inequality in mortality was larger than could be expected from inequalities in associated risk factors. We found large inequalities in mortality from alcohol-related causes, such as liver cirrhosis, UADT and liver cancer. Particularly in women, these inequalities were at odds with the low or reversed inequality in alcohol consumption. In France and Spain, inequality in alcohol-related cancer mortality was similar and could also not be explained by inequalities in alcohol consumption [15-17]. Possibly, telephone interviews may not be the best method to assess the full range of alcohol consumption. Moreover, persons with hazardous alcohol consumption may more often refuse to participate in health surveys than moderate drinkers or abstainers. In our study, we used inequalities in daily alcohol consumption (yes or no). However, for a part of the participants (72\%), the amount of ethanol consumed daily was available. A mere $3.4 \%$ reported daily intake that exceeded $60 \mathrm{~g}$ of ethanol, and $16 \%$ were abstainers. The inequality pattern resulting from alcohol consumers in the upper quintile (men $>71 \mathrm{~g}$, women $>27 \mathrm{~g}$ ) was similar to that of daily alcohol consumption (table 3 ) in men but not in women. In GS women, inequalities were not reversed (negative) as was the case for daily alcohol consumption, but positive (5\% decrease of those in the upper quintile per additional year of education). This could explain the larger inequality in UADT cancer in GS women.

In our study, the large inequalities in stomach cancer mortality in both regions could not be explained by 
similar inequalities in infrequent consumption of fruits, particularly in men. In contrast, in Germany, inequality in stomach cancer mortality in the late 1980 s could be explained by similarly large inequalities in fruit consumption $[15,18]$. We could not consider risk factors which are more specific for stomach cancer, such as Helicobacter pylori [19]. This bacteria is more likely to affect persons with low than with high SES [20]. Because of the increasing availability and affordability of fruits and vegetable, improved sanitary conditions and better diagnosis and treatment of Helicobacter pylori, inequalities in stomach cancer could further decrease [21].

In contrast to smoking and obesity, alcohol consumption can also be regarded as a protective factor against cardiovascular disease, particularly when consumed in a context of a healthy lifestyle [22,23]. However, when comparing FS and GS, inequalities in these risk factors did not consistently fit to inequalities in CHD mortality.

In line with the broader European pattern, in both regions, the relatively small inequalities in infrequent fruit consumption and physical inactivity failed to entirely explain variations in inequalities in CHD which were comparably large, particularly in women $[1,15,17,21]$. This could be due to the "healthy participant effect" of health surveys, to risk factor assessment or be a consequence of inequalities in treatment and diagnosis: For "harder" cardiovascular risk factors, such as high blood pressure, much larger inequalities in women than in men were found in Spain. Also, after cardiac surgery, SES inequalities in survival remained significant after adjustment for smoking, obesity and diabetes [24]. Several authors explained the significantly larger inequality in circulatory disease mortality in women compared to men by the poorer diagnosis and treatment in women with cardiovascular disease [25-27].

In both regions and sexes, smoking inequalities were comparably small and failed to explain the large gradient in lung cancer mortality, particularly in men. Larger inequalities in smoking and in lung cancer mortality in men than in women are typical for southern European countries $[1,21,28,29]$. We found this pattern predominantly in women, where inequalities in lung cancer tended to be larger in FS than in GS. For several reasons, we assume that in men the relation between smoking inequality and inequality in lung cancer mortality is underestimated in our figures. First, smokers and persons belonging to lower SES more often refuse to participate in health surveys than non-smokers [30]. Participating smokers may therefore represent a strongly selected population which is possibly also more prone to report social desirable behaviours [30]. Second, other risk factors for lung cancer are more frequent in persons in lower SES (e.g. air pollution, occupational exposures) and thus contribute to inequality in mortality [29].
Third, diagnosis and treatment possibly are better in those with higher SES irrespective of risk factors [24,31]. Thus, there may be a "double social inequality" in persons with low SES, arising from a higher risk for lung cancer and, once affected, a higher risk of dying from the disease [18]. Similar patterns also apply for inequality in COPD mortality, which was also large in women. As in lung cancer, international differences in COPD mortality could not be explained by differences in smoking [32]. In addition to above-mentioned factors, the increased risks of respiratory disease in farmers could map to the educational gradients [33].

Educational inequality in suicide may correspond to the European average for both sexes [34]. In contrast, in men, inequalities in transport accident mortality were larger in Switzerland than in most other European countries [35]. The relatively large inequality in mortality from transport accidents in men in both GS and FS as well as the substantial difference between these regions are in line with the large inequality in mortality from other causes of death related to alcohol consumption.

Self-rated health is a good predictor of mortality $[36,37]$. The inequality pattern (women $>$ men) in lessthan-good self-rated health could also be found on a European scale [1]. However, differences between GS and FS were much smaller than those between Germany and France [1]. Larger inequalities in less-than-good self-rated health in GS women were in line with larger inequalities in all-cause mortality. In accordance with the larger inequality in GS women, in Europe, inequalities in self-rated health are largest in countries with more egalitarian health policies such as Norway or the Netherlands [38]. In contrast to studies comparing northern and southern European countries, we have no evidence of different perceptions of health between the language regions $[11,39,40]$.

As shown in our previous publication, there were substantial variations in cause-specific mortality between Swiss regions and similar variations could be found on a broader European scale [7]. When a specific cause of death is more prevalent in one region than in another, one could expect unexploited potential for reduction of health inequalities. In our data, this has been confirmed by the fact that higher mortality from COPD in GS than in FS was accompanied by larger inequality in COPD mortality. Accordingly, higher mortality rates of alcoholrelated causes (UADT and liver cancer and liver cirrhosis) found in FS would lead one to expect larger inequalities in that region, but this was not the case. This discordance may relate to the fact that predominantly hazardous but not moderate drinking is responsible for cancer and cirrhosis. Hazardous drinking is only poorly captured by a questionnaire used in a health survey and 
reporting probably differs substantially, depending on cultural and social norms [41]. In addition to alcohol consumption, self-rated health as well as reporting height and weight (influencing obesity prevalence) may vary strongly between cultures $[39,42]$. In our previous study, only part of the variation in mortality between GS and FS could be explained by differences in risk factors [7].

In addition to inequality in risk factors, inequality in mortality could also be biased e.g., when assignment of causes of death depends on SES or on cultural peculiarities [7]. Comparisons between risk factors and mortality inequality should be interpreted cautiously. Most risk factors impact on mortality with a latency of 20 years or more. Thus, simultaneous assessments of inequality in mortality and risk factors only roughly reflect real associations. Also, on a population base, only cross-sectional $(1992 / 93)$ data on risk factors was available precluding interpretation of trends in risk factors and corresponding inequalities. However, comparisons with earlier (1977) and later (2002) assessments suggest that the prevalence of many major risk factors remained quite stable in the Swiss population $[43,44]$. Another limitation for comparison is coverage. The Swiss National Cohort covers the whole population and is based on mandatory data collection (census, vital statistics), whereas the health survey is a $3 \%$ sample with a participation rate of $71 \%$. Persons with an unhealthy lifestyle or belonging to lower socioeconomic groups are likely to be underrepresented in health surveys [30]. In fact, there are more persons with tertiary education in the survey than in the cohort which may hamper gradient comparison. A potential source of bias is also the use of education for determining inequality. In the Swiss federal system, there are in fact not only one but 26 educational systems. However, these variations coincide only partially with language regions and are much smaller than between countries.

\section{Conclusions}

Educational inequalities in mortality were substantial in Switzerland, particularly for causes with known risk factors (i.e., smoking, alcohol consumption, and obesity). In contrast, inequalities in most of these risk factors per se were smaller than expected. Since risk factors often occur together (cluster), their joint impact may better correspond to the inequality in mortality. In accordance with the broader European pattern, most mortality inequalities were larger in German- than in Frenchspeaking areas. However, this was at odds with generally larger inequalities in risk factors in French-speaking Switzerland. This discrepancy may be due to weaknesses in risk factor assessment and assignment of cause of death.

\section{Additional material}

Additional file 1: Appendix. Table S1 - Comparison of study populations, by sex and language region. Table S2 - Individuals included at 1990 census by region and sex, overall and \% by educational level. Table S3 - List of causes of death.

\section{Acknowledgements}

We are grateful to Christoph Minder for valuable advice and ongoing critical review of the manuscript, to Julia Braun for excellent advice in statistics, to Jen Wang for proofreading the final manuscript and to the referees for their constructive comments that substantially improved this paper. We thank the Swiss Federal Statistical Office for providing data for the Swiss National Cohort and from the Swiss Health Survey 1992/93. This study received financial support from the Swiss National Science Foundation (grant 33CSCO-108806)

The members of the Swiss National Cohort Study Group are Felix Gutzwiller (Chairman of Executive Board), Matthias Bopp (both Zurich), Matthias Egger (Chairman of Scientific Board), Adrian Spoerri, Malcolm Sturdy (Data manager) and Marcel Zwahlen (all Bern), Charlotte Braun-Fahrländer (Basel), Fred Paccaud (Lausanne) and André Rougemont (Geneva).

\section{Authors' contributions}

$M B$ conceived the study and sketched a first draft. MB and DF prepared the data file of the Swiss National Cohort, DF prepared the data file of the Swiss Health Survey 1992/93. DF wrote up the manuscript. Literature review, data analysis and interpretation of the results were performed by both authors, as well as repeated editing of the manuscript. Both authors read and approved the final manuscript.

\section{Competing interests}

The authors declare that they have no competing interests.

Received: 11 September 2009 Accepted: 22 September 2010 Published: 22 September 2010

\section{References}

1. Mackenbach JP, Stirbu I, Roskam AJ, Schaap MM, Menvielle G, Leinsalu M, Kunst AE: Socioeconomic inequalities in health in 22 European countries. N Engl J Med 2008, 358(23):2468-2481.

2. Bopp M, Minder CE: Mortality by education in German speaking Switzerland, 1990-1997: results from the Swiss National Cohort. Int J Epidemiol 2003, 32(3):346-354.

3. Mackenbach JP: Health inequalities: Europe in profile - An independent, expert report commissioned by the UK Presidency of the EU. Rotterdam: Dept. of Public Health, Erasmus MC 2006, 41

4. Kattainen A, Salomaa V, Harkanen T, Jula A, Kaaja R, Kesaniemi YA, Kahonen M, Moilanen L, Nieminen MS, Aromaa A, et al: Coronary heart disease: from a disease of middle-aged men in the late $1970 \mathrm{~s}$ to a disease of elderly women in the 2000s. Eur Heart J 2006, 27(3):296-301.

5. Lozano R, Murray CJL, Lopez AD, Satoh T: Miscoding and misclassification of ischaemic heart disease mortality. Global Programme on Evidence for Health Policy. Working Paper No 12. Volume Sept WHO 2001.

6. Lindeboom $M$, van Doorslaer $E$ : Cut-point shift and index shift in selfreported health. J Health Econ 2004, 23(6):1083-1099.

7. Faeh D, Minder C, Gutzwiller F, Bopp M: Culture, risk factors and mortality: Can Switzerland add missing pieces to the European puzzle? J Epidemiol Community Health 2009, 63(8):639-645.

8. Bopp M, Spoerri A, Zwahlen M, Gutzwiller F, Paccaud F, Braun-Fahrlander C, Rougemont A, Egger M: Cohort Profile: The Swiss National Cohort-a longitudinal study of 6.8 million people. Int J Epidemiol 2008, Published Online Fist: 7 March 2008.

9. Bundesamt für Statistik. Eidgenössische Volkszählung 2000. Abschlussbericht zur Volkszählung 2000. Statistik Bundesamt für. Neuchâtel 2005.

10. Bopp M, Gutzwiller F: Die Swiss National Cohort 1990-2000 - eine soziodemografische Datenbasis für longitudinale Gesundheitsanalysen. 
Swiss National Cohort Report Nr 5, Forschung und Dokumentation 30 Zürich: Institut für Sozial- und Präventivmedizin 2007.

11. International Standard Classification of Education, as designed by the United Nations Educational, Scientific and Cultural Organization (UNESCO). [http://www.unesco.org/education/information/nfsunesco/doc/ isced_1997.htm].

12. Eichholzer M, Bisig B: Daily consumption of (red) meat or meat products in Switzerland: results of the 1992/93 Swiss Health Survey. Eur J Clin Nutr 2000, 54(2):136-142.

13. Day NE: Cumulative Rate and Cumulative Risk. In Cancer incidence in Five Continents (IARC Scientific Publications No 42). Edited by: Waterhouse JAH, Muir CS, Shanmugaratnam K, Powell J. Lyon: International Agency for Research on Cancer; 1982:668-670.

14. Mackenbach JP, Kunst AE: Measuring the magnitude of socio-economic inequalities in health: an overview of available measures illustrated with two examples from Europe. Soc Sci Med 1997, 44(6):757-771.

15. Cavelaars AE, Kunst A, Mackenbach J: Socio-economic differences in risk factors for morbidity and mortality in the European Community. J Health Psychology 1997, 2(3):353-372.

16. Menvielle G, Kunst AE, Stirbu I, Borrell C, Bopp M, Regidor E, Heine Strand B, Deboosere $\mathrm{P}$, Lundberg $\mathrm{O}$, Leclerc $\mathrm{A}$, et al: Socioeconomic inequalities in alcohol related cancer mortality among men: to what extent do they differ between Western European populations? Int I Cancer 2007, 121(3):649-655.

17. Regidor $E$, Calle ME, Navarro P, Dominguez V: The size of educational differences in mortality from specific causes of death in men and women. Eur J Epidemiol 2003, 18(5):395-400.

18. Geyer S: Social inequalities in the incidence and case fatality of cancers of the lung, the stomach, the bowels, and the breast. Cancer Causes Control 2008, 19(9):965-974.

19. Forman D, Newell DG, Fullerton F, Yarnell JW, Stacey AR, Wald N, Sitas F: Association between infection with Helicobacter pylori and risk of gastric cancer: evidence from a prospective investigation. Bmj 1991 302(6788):1302-1305.

20. Boffetta P: Infection with Helicobacter pylori and parasites, social class and cancer. IARC Sci Publ 1997, , 138: 325-329.

21. Roskam A: Cross-national comparisons of socioeconomic differences in overweight and obesity. Erasmus University, Inst Maatschappelijke Gezondheidszorg 2009.

22. Breslow RA, Graubard BI: Prospective Study of Alcohol Consumption in the United States: Quantity, Frequency, and Cause-Specific Mortality. Alcohol Clin Exp Res 2008, 32(3):513-521.

23. Mukamal KJ, Chiuve SE, Rimm EB: Alcohol consumption and risk for coronary heart disease in men with healthy lifestyles. Arch Intern Med 2006, 166(19):2145-2150

24. Pagano D, Freemantle N, Bridgewater B, Howell N, Ray D, Jackson M, Fabri BM, Au J, Keenan D, Kirkup B, et al: Social deprivation and prognostic benefits of cardiac surgery: observational study of 44902 patients from five hospitals over 10 years. Bmj 2009, 338:b902.

25. Mackenbach JP, Kunst AE, Groenhof F, Borgan JK, Costa G, Faggiano F, Jozan P, Leinsalu M, Martikainen P, Rychtarikova J, et al: Socioeconomic inequalities in mortality among women and among men: an international study. Am J Public Health 1999, 89(12):1800-1806.

26. Vaccarino V, Berkman LF, Krumholz HM: Long-term outcome of myocardial infarction in women and men: a population perspective. Am J Epidemiol 2000, 152(10):965-973.

27. Clarke KW, Gray D, Keating NA, Hampton JR: Do women with acute myocardial infarction receive the same treatment as men? Bmj 1994, 309(6954):563-566.

28. Avendano M, Kunst AE, Huisman M, Lenthe FV, Bopp M, Regidor E, Glickman M, Costa G, Spadea T, Deboosere P, et al: Socioeconomic status and ischaemic heart disease mortality in 10 western European populations during the 1990s. Heart 2006, 92(4):461-467.

29. Mackenbach JP, Huisman M, Andersen O, Bopp M, Borgan JK, Borrell C, Costa G, Deboosere P, Donkin A, Gadeyne S, et al: Inequalities in lung cancer mortality by the educational level in 10 European populations. Eur J Cancer 2004, 40(1):126-135.

30. Jousilahti P, Salomaa V, Kuulasmaa K, Niemela M, Vartiainen E: Total and cause specific mortality among participants and non-participants of population based health surveys: a comprehensive follow up of 54372
Finnish men and women. J Epidemiol Community Health 2005, 59(4):310-315.

31. Woods LM, Rachet B, Coleman MP: Origins of socio-economic inequalities in cancer survival: a review. Ann Oncol 2006, 17(1):5-19.

32. Brown CA, Crombie IK, Tunstall-Pedoe H: Failure of cigarette smoking to explain international differences in mortality from chronic obstructive pulmonary disease. J Epidemiol Community Health 1994, 48(2):134-139.

33. Melbostad E, Eduard W, Magnus P: Chronic bronchitis in farmers. Scand J Work Environ Health 1997, 23(4):271-280.

34. Lorant V, Kunst AE, Huisman M, Costa G, Mackenbach J: Socio-economic inequalities in suicide: a European comparative study. $\mathrm{Br} J$ Psychiatry 2005, 187:49-54

35. Borrell C, Plasencia A, Huisman M, Costa G, Kunst A, Andersen O, Bopp M, Borgan JK, Deboosere P, Glickman M, et al: Education level inequalities and transportation injury mortality in the middle aged and elderly in European settings. Inj Prev 2005, 11(3):138-142.

36. DeSalvo KB, Bloser N, Reynolds K, He J, Muntner P: Mortality prediction with a single general self-rated health question. A meta-analysis. J Gen Intern Med 2006, 21(3):267-275.

37. Idler EL, Benyamini $Y$ : Self-rated health and mortality: a review of twentyseven community studies. J Health Soc Behav 1997, 38(1):21-37.

38. Cavelaars AE, Kunst AE, Geurts JJ, Crialesi R, Grotvedt L, Helmert U, Lahelma E, Lundberg O, Matheson J, Mielck A, et al: Differences in self reported morbidity by educational level: a comparison of 11 western European countries. J Epidemiol Community Health 1998, 52(4):219-227.

39. Jurges $\mathrm{H}$ : True health vs response styles: exploring cross-country differences in self-reported health. Health Econ 2007, 16(2):163-178.

40. von dem Knesebeck O, Verde PE, Dragano N: Education and health in 22 European countries. Soc Sci Med 2006, 63(5):1344-1351.

41. Legleye S: [Geography of French alcohol consumption]. Rev Epidemiol Sante Publique 2002, 50(6):547-559.

42. Gorber SC, Tremblay M, Moher D, Gorber B: A comparison of direct vs. self-report measures for assessing height, weight and body mass index: a systematic review. Obes Rev 2007, 8(4):307-326.

43. Gutzwiller F, Nater B, Martin J: Community-based primary prevention of cardiovascular disease in Switzerland: methods and results of the National Research Program (NRP 1A). Prev Med 1985, 14(4):482-491.

44. Eichholzer M, Bernasconi F, Jordan P, Gutzwiller F: Nutrition in Switzerland 2002-results of the Swiss Health Survey. Schweiz Rundsch Med Prax 2005, 94(44):1713-1721.

\section{Pre-publication history}

The pre-publication history for this paper can be accessed here: http://www.biomedcentral.com/1471-2458/10/567/prepub

\section{doi:10.1186/1471-2458-10-567}

Cite this article as: Faeh et al:: Educational inequalities in mortality and associated risk factors: German- versus French-speaking Switzerland. BMC Public Health 2010 10:567.

\section{Submit your next manuscript to BioMed Central and take full advantage of:}

- Convenient online submission

- Thorough peer review

- No space constraints or color figure charges

- Immediate publication on acceptance

- Inclusion in PubMed, CAS, Scopus and Google Scholar

- Research which is freely available for redistribution

Submit your manuscript at www.biomedcentral.com/submit
C Biomed Central 